\title{
Luta de classes entre trabalhadores e grande capital: as relações entre as facções e a empresa Guararapes no Rio Grande do Norte
}

\author{
William Eufrásio Nunes Pereira ${ }^{1}$ \\ Renata Rayane Moura da Silva Rodrigues ${ }^{2}$
}

\begin{abstract}
Resumo: O objetivo deste trabalho é analisar o conflito entre o Ministério Público do Trabalho (MPT) do Rio Grande do Norte e o grupo Guararapes, considerando o papel das facções e dos trabalhadores em meio ao conflito jurídico, econômico, político e ideológico travado por esses atores. De um lado da história está o grande capitalista, de outro, trabalhadores em atuação como costureiros e aqueles a quem o MPT denomina "travestidos de microempresários". Essas duas categorias assumem o papel dos que vendem a força de trabalho para subsistir e, nesse caminho, submetem-se ao controle do capitalista, a regras unilaterais, à pressão por produtividade e à redução de direitos. $\mathrm{O}$ artigo expõe esse paralelo com base em supostas irregularidades que o MPT investigou na contratação e no modo de operação de "facções da Guararapes". Tais irregularidades fundamentam uma ação civil pública e mostram que discurso e práticas de mais de um século atrás ainda alimentam a linha de produção. A metodologia usada neste trabalho inclui pesquisa bibliográfica e documental. Resultados encontrados mostram um intenso conflito entre capital e trabalho, no qual o primeiro amplia seus lucros com a redução dos custos, em particular, os do trabalho.
\end{abstract}

Palavras-chave: Capital. Facções. Indústria. Marx. Trabalho.

\section{Class struggle between workers and big capital: the relations between the factions and the Guararapes company in Rio Grande do Norte}

\begin{abstract}
The objective of this work is to analyze the conflict between MPT-RN. and the Guararapes group, considering the role of factions and workers in the midst of the legal, economic, political and ideological conflict waged by these actors. On one side of the story is the great capitalist; on the other, we have the workers that are employed as dressmakers/tailors and the ones that the District Attorney Office for Labour label as the "disguised as small-business owners". These two categories assume the role of those who sell their labour force in order to subsist and, this way, submit themselves to the capitalist's control, to one-sided rules, pressure for productivity and reduced rights. The article exposes this parallel based on alleged irregularities that the DA Office investigated in the hiring and operation of "facções of Guararapes". Such irregularities underlie a public civil action and show that discourse and practices from over a century ago still feed the production line. The methodology used in this work includes bibliographic and documentary research. Results found show an intense conflict between capital and labour, in which the first one increases its profits by reducing costs, particularly those of labour.
\end{abstract}

Keywords: Capital. Factions. Industry. Marx. Work.

\footnotetext{
${ }^{1}$ Bacharel em Direito e Economia. Mestre em Economia (UFPB). Doutor em Ciências Sociais (UFRN). E-mail: wenpereira2014@gmail.com.

2 Jornalista graduada pela Universidade Federal do Rio Grande do Norte (UFRN). Especialista em Agronegócios pela Escola Superior de Agricultura Luiz de Queiroz, da Universidade de São Paulo (Esalq/USP). Mestranda em jornalismo investigativo pela Birkbeck University of London. Estudante de economia (UFRN). E-mail: rr_moura_silva@hotmail.com.
} 


\section{Introdução}

O ano de 2013 terminou com um lucro líquido33 de $\mathrm{R} \$ 420,6$ milhões para a Guararapes que, naquele ano, formada por 212 pontos de venda no país, apresentava-se como o maior grupo empresarial de moda do Brasil e controlador da rede varejista Lojas Riachuelo (GUARARAPES, 2014). A estrutura engloba fábricas de confecção instaladas na região Nordeste, nos estados do Rio Grande do Norte e Ceará, de onde saíram 39,5 milhões de peças de vestuário naquele ano. O período foi marcado por um crescimento de 15,1\% no lucro do grupo (GUARARAPES, 2014) e pelo início da terceirização de parte dos serviços de costura da indústria por meio da contratação de facções.

Entre 2005 e 2013, a área de vendas do grupo já havia experimentado uma expansão de 184\%, saindo de 172,8 mil metros quadrados para 490,0 mil metros quadrados, e o plano, àquela altura, era de um crescimento ainda maior. Em setembro de 2013, quando englobava 183 lojas, a expectativa era dobrar a produção própria até 2018 e duplicar o número de pontos de venda no país (MOURA, MENDES, 2013). Para alcançar esse objetivo, uma das estratégias foi a decisão de terceirizar parte da produção por via das facções.

As facções, que ajudariam a aquecer a linha de produção da indústria para abastecer as lojas, seriam criadas no interior do Rio Grande do Norte com o estímulo do Programa de Interiorização da Indústria Têxtil, o denominado Pró-Sertão. O programa apoiaria a implantação de empresas de confecções inicialmente no Seridó do estado, região com tradição nessa atividade4. Um dos objetivos seria "contribuir para a geração de emprego e renda em regiões de baixo desenvolvimento econômico" [...], além de "promover a geração de vínculos de negócios sustentáveis entre grandes empresas - âncoras do programa - e suas micro e pequenas empresas fornecedoras, localizadas no interior do Estado" (SEDEC, sem data,; A REPÚBLICA, 2015, p. 1).

Inspeções realizadas pelo Ministério Público do Trabalho (MPT-RN, 2017) em 43 das unidades que prestavam serviços à Guararapes apontaram, no entanto, irregularidades no modelo de contratação e operação desses negócios e puseram em xeque os resultados pretendidos. Tais irregularidades levaram à abertura de uma Ação Civil Pública (ACP) contra o grupo, dois anos após o lançamento do Programa.

Nessa ação, tecnicamente chamada de ACP 0000694-45.2017.5.21.0007, mas que neste artigo será identificada por extenso, ou alternadamente como ACP, o MPT-RN alega que a grande indústria tem contratado as facções como meras intermediadoras de mão de obra sob seu estrito controle e em meio a um sistema de forte pressão por produtividade, baixas remunerações, redução de garantias sociais,

\footnotetext{
${ }^{3}$ Informações disponíveis na apresentação dos resultados do grupo:

$<\underline{\text { https://ri.riachuelo.com.br/listresultados.aspx?idCanal=SEIpANecjCAH5uaTCxPYdw }>}$

${ }^{4}$ Ler mais sobre o programa nas reportagens: Costurando o Desenvolvimento (http://www.tribunadonorte.com.br/costurandoodesenvolvimento/) e Pró-Sertão promete impulsionar RN, disponível em: $<$ http://www.tribunadonorte.com.br/noticia/pro-sertao-promete-impulsionar-rn/257636> Acesso em 21 de outubro de 2019.
} 
violação de direitos trabalhistas e grande dependência econômica, com consequências quando os pedidos são suspensos.

O uso das facções seria um meio de o grupo reduzir custos de operação e se livrar de possíveis obrigações trabalhistas, caso incorporasse diretamente os trabalhadores para reforçar a etapa da costura do vestuário (MPT-RN, 2017, p. 65-66). O imbróglio estava assim estruturado: MPT versus Guararapes.

A análise do conflito, tema deste artigo, é relevante porque é um momento em que o Brasil se vê em meio a mudanças nas relações patrão-empregado, com a aprovação da lei da terceirização e da reforma trabalhista. Ademais, o caso envolvendo a Guararapes e as facções ganhou ampla repercussão na mídia brasileira e gerou manifestações em favor do capital por parte não só de empresários, mas também do governo do Rio Grande do Norte e de trabalhadores das pequenas unidades de produção que foram às ruas anunciar a defesa dos seus contratos de trabalho.

Para comparar a atuação dos agentes econômicos e políticos envolvidos nesse cenário, este artigo se fundamenta não só na leitura de $\mathrm{O}$ Capital, mas também em outros autores que escreveram sobre o capitalismo e a teoria marxista. Analisam-se os fundamentos da ação civil movida pelo Ministério Público do Trabalho contra a Guararapes, assim como entrevistas de representantes da indústria, de trabalhadores e de donos de facções, veiculadas na mídia. Do ponto de vista metodológico, trata-se de pesquisa exploratória, a qual, segundo Prodanov e Freitas (2013, p. 52), abrange, em geral, as pesquisas bibliográficas e os estudos de caso. A pesquisa bibliográfica e a pesquisa documental foram, portanto, os principais procedimentos adotados para colher as informações que ajudam a estruturar este texto. Entre as fontes estão bases de dados públicas on-line, que mostram indicadores do emprego no setor de confecções, além de demonstrações financeiras do grupo Guararapes, com detalhamento do tamanho da operação.

O objetivo deste trabalho é analisar o conflito entre o MPT-RN e o grupo Guararapes, considerando o papel das facções e o dos trabalhadores em meio ao conflito jurídico, econômico, político e ideológico travado por esses atores. Propõe-se, em outras palavras, uma interpretação marxista da ação civil pública movida pelo MPT-RN. A metodologia empregada inclui pesquisa bibliográfica e documental. Por meio da pesquisa documental, apresenta-se o contexto do conflito. A pesquisa bibliográfica contribui para a compreensão categórica e conceitual dos fatos atuais, suas implicações e possíveis corolários.

\subsection{As facções e os trabalhadores em meio ao conflito entre o MPT e a Guararapes}

O Serviço Brasileiro de Apoio à Micro e Pequena Empresa (apud GALINDO, 2018, p. 18) assim define facção: "confecções que prestam serviços [...] realizando somente trabalhos de corte, montagem e acabamento de peças do vestuário para outras confecções”. Em 2013, a Guararapes anunciou que passaria a contratar esse tipo de empresa para dar vazão aos planos de crescimento da Riachuelo. Análises apresentadas pelo grupo à época apontavam, para atender à demanda da varejista, seria necessária uma produção em torno de 150 mil a 160 mil peças por dia, o que significaria contratar de 300 a 350 facções, com aproximadamente 30 pessoas cada (AMORIM, 2013).

\begin{tabular}{|l|l|l|l|l|l|l|l|c} 
Cadernos de Ciências Sociais Aplicadas & ano XVIII & vol. 18 & $n^{\circ} 31$ & págs. 207-228 & jan./jun. 2021 & UESB & Vitória da Conquista/BA & pág. 209 \\
\hline
\end{tabular} 
O volume global de vendas do varejo de tecidos, vestuário e calçados cresceu 3,5\%, no Brasil, em 2013 (IBGE, 2013). Com ritmo acelerado, a Riachuelo atingiu um avanço na receita líquida consolidada de mercadorias da sua rede de lojas de 17,6\%, somando $\mathrm{R} \$ 3,29$ bilhões. As vendas líquidas nas mesmas lojas, que consideram as vendas em lojas abertas há mais de um ano, subiram 7,3\% em relação a 2012 (GUARARAPES, 2014).

As facções eclodiram com o programa Pró-Sertão, lançado em 2013, resultado de uma parceria entre o Governo do Rio Grande do Norte, a Federação das Indústrias do estado (Fiern) e o Serviço Brasileiro de Apoio à Micro e Pequena Empresa (Sebrae) ${ }^{5}$. O objetivo era incentivar a economia do semiárido do Rio Grande do Norte, com foco na micro e pequena indústria de confecção (SEBRAE, 2017, p.4), e atender à demanda de grandes empresas do varejo de moda, tais como a Guararapes e a Hering (SEBRAE, 2016, p. 135).

A expectativa anunciada no lançamento era de que até dezembro de 2018 fossem criadas 360 unidades de facção, gerados cerca de 20 mil postos de trabalho e qualificados milhares de profissionais (GOVERNO DO RN, 2013, FIERN, 2017). Empresários que já atuavam no setor de confecções em pequena escala e novos empreendedores que pretendiam aproveitar a oportunidade comercial foram chamados a se inscrever no programa (GOVERNO DO RN, 2013).

Como incentivos, foram apresentadas perspectivas não só de mercado, mas também de apoio para estruturação dos negócios de forma sustentável, o que inclui capacitação de profissionais como operadores e mecânicos de máquinas de costura, orientações para abertura e legalização das empresas, capacitação e consultoria empresarial, rodadas de negócio para acesso aos potenciais mercados (FIERN, 2017 e SEBRAE, SEM DATA) e linhas de crédito para compra e expansão de maquinário (TRIBUNA DO NORTE, 2018).

O elevado e rápido crescimento no número de facções e de empregos, aliado a várias denúncias de trabalhadores demitidos levou o MPT-RN a investigar o programa governamental e a impetrar ação civil pública (MPT-RN., 2017, p. 99) para que a Guararapes assuma a contratação direta ou reconheça a responsabilidade solidária no cumprimento dos direitos e encargos decorrentes dos contratos de emprego firmados pelas facções, conforme detalhado no trecho a seguir:

O Ministério Público do Trabalho requer que seja reconhecido vínculo de emprego entre a ré e todos os trabalhadores atuais e futuros contratados por meio das facções [...]; que seja condenada a registrar todos os vínculos de emprego reconhecidos e a adotar em todos os estabelecimentos de facções as medidas legais de proteção ao meio ambiente do trabalho [...]; que caso não seja reconhecido vínculo de emprego entre as partes, que seja reconhecida a configuração de grupo econômico industrial entre a Guararapes e todas as facções que lhe prestam serviços, reconhecendo-se a responsabilidade solidária da ré pelo cumprimento de todos os direitos e encargos decorrentes dos contratos de empregos firmados pelas facções, inclusive o registro de emprego, o cumprimento dos direitos previstos em normas coletivas, a adoção das medidas de proteção ao meio ambiente do trabalho, no curso dos contratos de emprego, e a igualdade salarial em relação aos empregados diretamente contratados (MP'T-RN., 2017, p. 99).

\footnotetext{
${ }^{5}$ Pró-Sertão promete impulsionar RN. Disponível em http://www.tribunadonorte.com.br/noticia/pro-sertaopromete-impulsionar-rn/257636.
} 
A ação tem por objetivo a condenação da indústria ao pagamento de indenização por danos morais coletivos no valor de $\mathrm{R} \$ 37,72$ milhões. A cifra considera o lucro líquido consolidado de $\mathrm{R} \$ 317,60$ milhões do grupo em 2016, o lucro líquido da Riachuelo, de $\mathrm{R} \$ 221,90$ milhões, e a transferência de 17\% da produção de sua fábrica no Rio Grande do Norte para as facções (MPT-RN., 2017, p. 92). O MP afirma que esses $17 \%$ representam a contribuição dos pequenos negócios para o lucro do grupo e deduz que "o valor obtido com a prática ilícita de intermediação de mão de obra foi de R \$37,72 milhões", sendo esse o montante do pedido de indenização.

\subsection{Terceirização como estratégia de apropriação da mais-valia}

A terceirização, conforme Marcelino e Cavalcante (2012), constitui uma das formas de subcontratação. Os autores declaram que, "na realidade brasileira, a terceirização é inseparável da ampliação da exploração do trabalho, da precarização das condições de vida das classes trabalhadoras", e complementam:

[...] ela não teria a abrangência que tem hoje se não fosse a sua capacidade de reduzir custos - e, portanto, de servir como poderoso instrumento para a recomposição das taxas de lucro - e de transferir para outras empresas (as contratadas) o "problema trabalhista", a necessidade de administração da força de trabalho e de negociação com ela e seus sindicatos (MARCELINO, CAVALCANTE, 2012).

Palmeira Sobrinho (2006, p. 44) argumenta, nesse mesmo sentido, que a razão principal de o detentor do capital recorrer à terceirização é a maior possibilidade de extração ou apropriação da maisvalia ${ }^{6}$, apresentada por ele como uma consequência específica do processo de produção capitalista, obtida por meio do sobretrabalho, ou seja, do excedente do tempo de trabalho socialmente necessário para pagar o salário do operário. $\mathrm{O}$ argumento é usado para contextualizar a reestruturação produtiva e a terceirização na indústria do petróleo, mas alinha-se também a análises que se debruçam especificamente sobre a indústria têxtil e de vestuário. Krost e Brandão (2017, p.165), por exemplo, observam que, nesses segmentos, a "terceirização" ganhou a alcunha de "faccionamento" devido ao repasse de diversas etapas da produção para "facções". Advertem também que a flexibilidade proporcionada por esse regime trouxe ganhos de competitividade e de lucratividade para o capital, mas isso ocorreu "à custa da precarização do trabalho, em níveis pouco conhecidos ou até mesmo ignorados pela sociedade que acaba assumindo uma parcela dos riscos".

Keller e Garcia (2015, p.122) reforçam a ideia de que empresas detentoras de marcas consagradas, que terceirizam a produção, veem seus lucros se tornarem "maiores quando deixam de existir os custos

6 Mais-valia, em O Capital, é apresentada como o acréscimo ou o excedente sobre o valor original de um produto (MARX, 2017, p. 181). É ela, segundo Marx, que transforma o dinheiro em capital (p.191). A mais-valia decompõese em lucros, juros e dízimo (MARX, 2017, p.256) e se origina de um excedente quantitativo de trabalho (p. 231). Marx observa que "quando o trabalhador opera além dos limites do trabalho necessário (...) gera a mais-valia" (p. 253). O trabalhador emprega mais da metade de seu dia de trabalho para criar mais-valia, diz Marx (p. 257). 
pertinentes à fabricação das peças, [...] repassados para as pequenas empresas". Ao analisar a terceirização da produção na indústria do vestuário em Curitiba, os autores vão além:

Por trás da chamada "parceria de negócios", na realidade o que se observa é um contrato de exploração que recai pesadamente sobre os trabalhadores das facções. Para as detentoras das marcas, é um "alívio"; porém, para as pequenas empresas produtoras, ao se observar suas realidades cotidianas, pode-se dizer que é um "desespero" (KELLER E GARCIA, 2015, p. 122).

\subsection{Divisão do trabalho: quem perde e quem ganha}

O modo de produção capitalista é um regime em que os meios de produção se tornaram um monopólio nas mãos de uma classe social e os produtores, separados desses meios de produção, são livres, mas desprovidos de todos os meios de subsistência — devendo, consequentemente, vender sua força de trabalho aos donos desses meios de produção (MANDEL, 196?). A divisão do trabalho na manufatura, classicamente exemplificada por Smith (2012) com uma fábrica de alfinetes, em que aproximadamente dezoito operações distintas e diferentes trabalhadores são necessários para obter o produto final, é apresentada por Marx, em O Capital, como uma criação específica do modo de produção capitalista (MARX, 2017, p. 414).

Essa criação, segundo o autor, “[...] pressupõe a autoridade incondicional do capitalista sobre seres humanos transformados em simples membros de um mecanismo que a ele pertence" (2017, p. 411), "produz novas condições de domínio do capital sobre o trabalho" e "[...] é apenas um método especial de produzir mais-valia relativa ou de expandir o valor do capital [...] à custa do trabalhador" (2017, p. 420). A divisão do trabalho, para Marx, "revela-se, de um lado, progresso histórico e fator necessário do desenvolvimento econômico da sociedade, e, de outro, meio civilizado e refinado de exploração (MARX, 2017, p. 420)".

O lado positivo é que esse sistema, decorrente da combinação de diferentes trabalhos dentro de uma mesma unidade de produção ou da subdivisão de um mesmo ramo de produção em manufaturas diversas (MARX. 2017, p. 408), aumenta a produtividade das indústrias. Em contrapartida, aponta Marx, "não só o trabalho é dividido e suas diferentes frações são distribuídas entre os indivíduos, mas o próprio indivíduo é mutilado e transformado no aparelho automático de um trabalho parcial [...] (MARX, 2017, p. 415)".

Marx aprofunda essa análise no seguinte trecho de O Capital, em que trata também da reação do capitalista quando tem seu modo de operação questionado:

O mesmo espírito burguês que louva, como fator de aumento da força produtiva, a produção manufatureira do trabalho, a condenação do trabalhador a executar perpetuamente uma operação parcial e sua subordinação completa ao capitalista, com a mesma ênfase denuncia todo controle e regulamentação sociais conscientes do processo de produção como um ataque aos invioláveis direitos de propriedade, de liberdade e de iniciativa do gênio capitalista. (MARX, 2017, p. 411). 
A contratação de facções de costura pela Guararapes, questionamentos levantados pelo Ministério Público do Trabalho acerca desse regime e a reação do empresário Flávio Rocha, presidente da Riachuelo e vice-presidente do grupo Guararapes, carregam em si elementos apresentados nessa teoria.

A grande indústria de confecção, que já opera com a divisão do trabalho dentro de suas fábricas, expande esse sistema para além de sua estrutura oficial, ao transferir a responsabilidade de parte de sua produção para outras empresas. No caso das facções, a fatia recebida foi a atividade de costura.

Sob a ótica do MPT-RN (2017, p. 3), as facções constituem pequenos parques industriais montados mediante o estímulo e orientação da Guararapes, para atendimento de suas demandas, com maquinários específicos para costura dos tipos de peças enviados pela companhia. Parte do modo de operação é detalhada no trecho a seguir:

Por meio de empresas transportadoras, elas recebem, então, as peças de roupas cortadas, acompanhadas dos aviamentos [...] como linha, zíper, elástico e etiquetas. Seguem, por e-mail, a Ordem de Produção e a Ficha Técnica especificando como a peça deve ser produzida (MPT-RN, 2017, p. 25 e 29).

\subsection{A ocupação no ramo de vestuário}

Do universo de 603.541 pessoas ocupadas no Rio Grande do Norte até o ano 2017, 19.929 atuavam na confecção de artigos de vestuário e acessórios (IBGE, CEMPRE, 2017). Esse número corresponde a 3,30\% do total de trabalhadores no estado, mas, se analisado no contexto apenas da indústria de transformação, ganha relevância e novos contornos: os quase 20 mil no ramo da confecção representavam $37,88 \%$ da mão de obra do setor, alçando a atividade ao posto de maior empregadora (IBGE, CEMPRE, 2017) - e a Guararapes à posição de destaque entre as indústrias de confecções em operação no território.

Estima-se que cerca de 9 mil dos 19.929 trabalhadores na confecção de vestuário e acessórios no estado - ou 45,79\% deles - atuavam diretamente na linha de produção dessa indústria, em 2017. O número é calculado com base no total de 13.037 colaboradores existentes nas fábricas do grupo naquele ano (GUARARAPES, 2017) e de uma estimativa, segundo a qual quase $70 \%$ dos empregados na área industrial própria atuavam no Rio Grande do Norte ${ }^{7}$ (MOURA E VASCONCELOS, 2016).

Marx trata do "ramo de vestuário" no capítulo 13 de O Capital, sobre a maquinaria - quando discute a "revolução que a indústria moderna realiza na manufatura, no artesanato e no trabalho a domicílio" (MARX, 2017, p. 534-538). Nesta última categoria, enquadra o trabalho realizado com máquinas de costura - instrumento que na visão dele "constitui, de início, apenas novo fator para a exploração manufatureira” (MARX, 2017, p. 537). Nessa passagem, Marx se refere à confecção de roupas femininas, "em que o trabalho, na sua maior parte, já estava organizado, com o predomínio da cooperação simples", mas cita também alfaiatarias, camisarias e sapatarias. O autor explica como funciona esse sistema de produção: 
Ora se encontra o sistema fabril, ora intermediários que recebem matérias-primas do chefe capitalista e agrupam em quartos ou sótãos 10 a 50 assalariados, às vezes mais, para trabalharem com as máquinas de costura. [...] O sistema que prepondera atualmente na Inglaterra é o de o capitalista concentrar grande número de máquinas em seus estabelecimentos, distribuindo depois o produto feito a máquina a um exército de trabalhadores a domicílio, encarregados da manipulação subsequente (MARX, 2017, p. 537).

A análise poderia ser facilmente aplicada à realidade das facções de costura que começaram a proliferar a partir de 2013 no Rio Grande do Norte. Nesse caso, o que Marx dizia naquela época ocorrer em cômodos de casas transformados em unidades de produção seria aplicado agora aos galpões nos quais se convencionou montar as "modernas" unidades especializadas em costura.

Marx apresenta os trabalhadores em domicílio como "[...] a seção externa das manufaturas, dos estabelecimentos comerciais e das pequenas oficinas dos mestres artesãos (MARX, 2017, p. 535)". Um cenário semelhante ao regime de funcionamento das facções era enxergado nessas manufaturas, como descreve nesse mesmo capítulo:

A grande indústria mecanizada fornece a massa material de trabalho, as matériasprimas, os produtos semi-acabados etc. e a massa de material humano barato, à mercê de exploração mais implacável e constituída por aqueles que perderam seus empregos na indústria e agricultura mecanizadas (MARX, 2017, p. 535).

No caso das facções de costura contratadas pela Guararapes, "essa massa” é formada, em sua maioria, por aqueles que não encontram alternativas de ocupação em suas cidades de origem ou, por exemplo, por ex-agricultores que atuavam sem carteira assinada.

Conforme descrito na ação movida pelo Ministério Público do Trabalho (MPT-RN, 2017, p.22), promessas da Guararapes de que "bastaria que os faccionistas costurassem as peças nos tempos cronometrados [...], para manter os empreendimentos em pleno funcionamento com lucratividade", atraíram diversos interessados em investir na área. Muitos desses potenciais empreendedores até então atuavam nos setores de comércio, serviços e indústria, como demonstrado neste trecho da ação:

Sob essa promessa, professores, servidores públicos, empregados de unidades hospitalares, de escritórios de contabilidade, de empresas de água mineral, de turismo, de segurança, de sondagens e análises de solos, de mineração, de produtos farmacêuticos, de comércio varejista de alimentos, móveis, carros e motos; de indústria de massas, empresas de terceirização e construções e hotéis [...], além de engenheiros de segurança, donas de casa, motoristas autônomos de caminhão e recepcionistas montaram facções e passaram a trabalhar sob ordens e controle direto e diário da Ré, submetidos primeiro às inspeções nos estabelecimentos pelos "gerentes de relacionamento", e, atualmente, submetidos ao próprio setor estruturado no âmbito da GUARARAPES para controle da atividade das facções [...] (MPT-RN, 2017, p. 22).

Nesse contexto, trabalhadores e donos de facções passaram a apresentar a criação dessas pequenas empresas como uma espécie de salvação, como descrevem costureiros dessas fábricas em depoimentos veiculados na mídia. Em declarações ao jornal Tribuna do Norte, a costureira Joilma Cilene revela o grau de dependência da cidade de São José do Seridó das facções: 
Aparecer esse emprego foi uma benção aqui para todos nós. Porque aqui não tinha o que fazer. Aí quando abriu essa facção foi o que deu emprego aos jovens e as pessoas que moram na comunidade (CILENE, 2017).

O também costureiro Maciel Alves reforça essa subordinação:

Se eu não tivesse esse emprego, eu me imaginaria fazendo o que da vida? Ia fazer o quê?", questiona ele e completa que esse é "o único ramo de ganho na cidade" e que com a facção tira o sustento e "ainda um pouco para conseguir mudar de vida (ALVES, 2017).

Em 2013, quando as facções começaram a ser contratadas pela Guararapes, outros trabalhadores já ressaltavam a importância do emprego nessas unidades. Foi o que fez, por exemplo, Leonardo Lima de Vasconcelos $^{8}$, naquela época, gerente de produção em uma facção de São José do Seridó (RN). Antes de se tornar empregado na unidade, ele e a família sobreviviam da agricultura e da pecuária, atividades em que a renda era incerta e era preciso acordar antes do sol nascer para iniciar os trabalhos. Vasconcelos ressaltou que agora, entre outras vantagens, o novo trabalho lhe permite saber quanto vai trabalhar e ter o salário garantido.

Ao retratar o cenário encontrado na Inglaterra mais de 150 anos antes, Marx declara que "as manufaturas do ramo de vestuário devem sua origem principalmente à necessidade do capitalista de ter à mão um exército de trabalhadores pronto a atender a qualquer flutuação de procura" (MARX, 2017, p. 535). Esse "exército" é uma necessidade percebida também na atual fase da indústria, que opera com empresas terceirizadas responsáveis por assumir parte da produção.

Invernizzi (2000, p. 3) observa, acerca da indústria brasileira, que "o amplo recurso à subcontratação se constitui numa das ferramentas fundamentais de flexibilização e redução de custos".

Este processo, iniciado nos anos 80, se expande significativamente na década atual em todos os setores estudados. Mais recentemente, a instalação ou relocalização de plantas industriais em regiões que dispõem de amplas reservas de mão-de-obra barata e sem passado industrial, se configura como outra via de redução de custos e de reformulação do perfil da força de trabalho empregada. Esta última estratégia está sendo amplamente utilizada pelas indústrias automobilística, têxtil e calçadista (INVERNIZZI, 2000, p. 3).

Segundo essa autora, tanto o processo de subcontratação quanto o de descentralização "contribuem para a crescente diferenciação das condições de emprego, cada vez mais precárias e instáveis para um setor importante da classe trabalhadora". Ela vai além, referindo-se à indústria de forma geral:

Além de outros benefícios, as empresas procuram nestas novas localizações uma força de trabalho sem passado industrial nem sindical e ávida de integrar-se ao trabalho assalariado, garantindo assim, maiores índices de adesão e maior plasticidade para aceitar as novas condições produtivas” (INVERNIZZI, 2000).

8 Depoimento concedido em setembro de 2013 à Tribuna do Norte:

< http://www.tribunadonorte.com.br/costurandoodesenvolvimento/\#emprego > Acesso em 10 de agosto de 2019. 


\subsection{Contratação de facções e menos empregos na Guararapes}

No caso da Guararapes, a contratação de facções para reforçar a produção começou em 2013, quando o governo do Rio Grande do Norte lançou o programa Pró-Sertão. O objetivo anunciado para o programa era estimular a criação de pequenas confecções no interior do estado para atender a demanda de indústrias maiores, o que, consequentemente, geraria mais emprego e renda na produção. A expectativa era “o incentivo ao empreendedorismo, especialmente nas regiões mais carentes do sertão do Estado, com mão de obra disponível e barata” (MPT-RN, 2017, p. 8).

Em inspeções que fundamentam a ação civil pública para averiguar a subcontratação praticada por intermédio da atividade de facção de vestuário e suas repercussões sobre os direitos sociais dos trabalhadores, o MPT-RN observa que o programa foi concebido para atender aos interesses principalmente da Guararapes e que esta empresa é a única ou maior contratante dos serviços das integrantes do programa. Esse papel que a Guararapes teria assumido é descrito no seguinte trecho da ação:

É evidente a dependência econômica das facções do Rio Grande do Norte em relação à Guararapes, na medida em que a facção se institui e se estrutura para fornecer atividade de costura altamente especializada à Guararapes, conforme sua específica demanda de costura (peças em jeans), sob preço de costura (e, por conseguinte, margem de lucro) estabelecido unilateralmente pela tomadora, conforme seus parâmetros produtivos (relação resultado/tempo) rigidamente fixados, sujeitando-se ao total controle operacional e administrativo da tomadora. [...] A Ré seleciona para permanecer no mercado, por ela criado, as empresas de facção que lhe atendem sob seus padrões de produtividade e segurança (menores riscos), descartando e abandonando à falência as facções que não se sujeitam a esses critérios, consideradas nas auditorias internas como de "alto risco" [...]. (MPT-RN., 2017, p. 46)

Em entrevista ao programa Roda Viva, Flávio Rocha, vice-presidente da Guararapes, dimensiona o exército que costura as roupas do grupo nas facções:

O Pró-Sertão, que é esse programa de descentralização da costura, já era para estar com 300 fábricas. Esse era o nosso projeto. Em praticamente todos os municípios. (...) Hoje tem 60 , com 5 mil empregos. Era para ter 5 vezes mais. Era para ter 25 mil empregos (ROCHA, 2017).

Essa quantidade de empregos gerada nas facções que costuram para a Guararapes (5 mil) é próxima do total de trabalhadores que o grupo dispensou nas duas fábricas próprias que operam no Rio Grande do Norte e no Ceará, conforme mostram dados disponíveis nos relatórios de divulgação dos resultados do grupo 9

Entre 2012 - ano em que se passou a divulgar publicamente o número de colaboradores por setor de atuação - e 2016, um ano antes de este artigo ser originalmente escrito, houve uma redução de 4.670 postos de trabalho nas fábricas, considerando não só as do Rio Grande do Norte, mas também as do

\footnotetext{
9 Disponíveis na área de relações com investidores do site da Riachuelo, disponível em:
} $<$ http://ri.riachuelo.com.br/> Acesso em 08 de agosto de 2019. 
Ceará. O total de empregados, nesse período, passou de 17.778 para 13.108 , um recuo de 26,26\% (GUARARAPES, 2013 e 2017).

Na ação civil pública, o MPT classifica a criação do Pró-Sertão de “fraude” (MPT-RN, 2017, p.91), “como alegado instrumento de geração de empresas autônomas e de novos empregos". As razões para essa avaliação são demonstradas a seguir:

[...] na realidade, houve a diminuição do número de empregos no parque fabril da Ré e transferência desses empregos para o interior do Estado, com menos direitos assegurados aos empregados e a criação, não de empresas autônomas, mas de verdadeiras unidades de produção da Ré em estabelecimentos de terceiros (MPT-RN, 2017, p. 91).

No gráfico 1, apresenta-se a trajetória dos empregos diretos do grupo a partir de 2012, ano que antecedeu o início da contratação das facções:

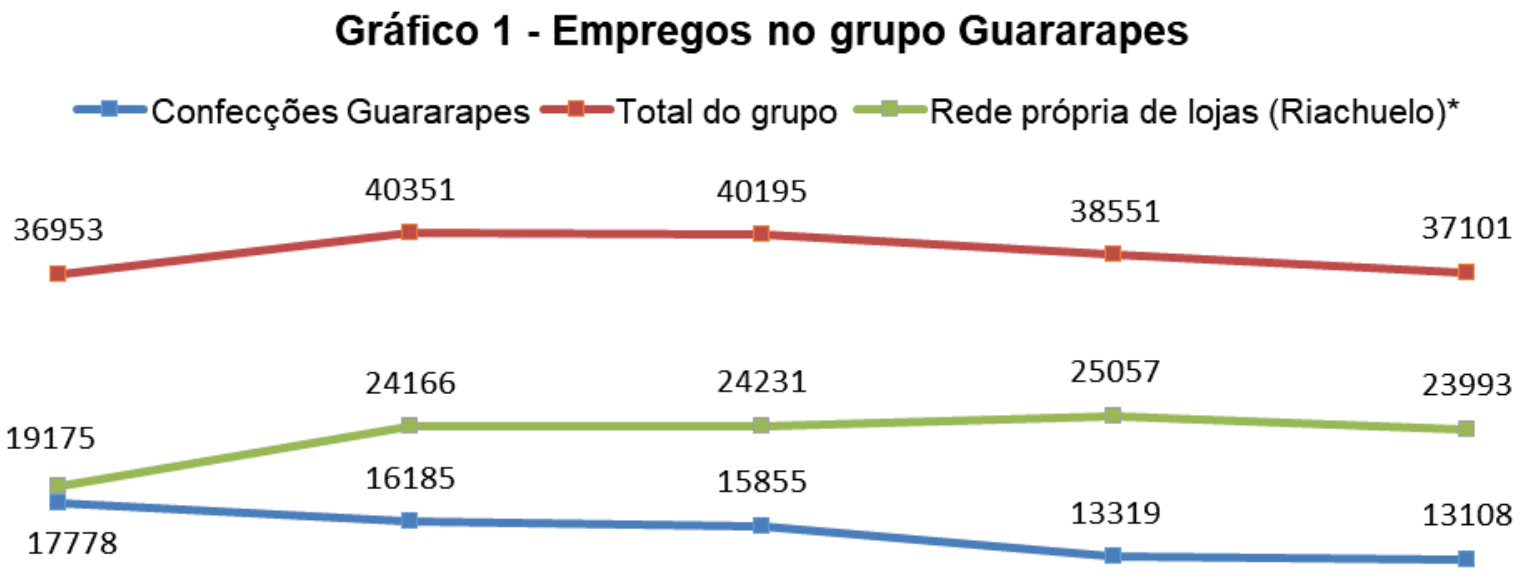

$\begin{array}{llll}2012 & 2013 & 2014 & 2015\end{array}$

Fonte: Elaboração própria, com base nos resultados do grupo.

*O grupo afirma que a expansão da Riachuelo o levou a contratar facções. O gráfico mostra, no entanto, que o ano de início desse movimento coincide com a queda do emprego no parque industrial próprio.

A participação das fábricas próprias no total de empregos do grupo, que chegava a 48,10\% em 2012, no final de 2016 estava em 35,33\%. Nesse mesmo período, a produção realizada nessas unidades e a participação no volume vendido na Riachuelo também recuaram. Na entrevista ao programa Roda Viva, Flávio Rocha comentou sobre esse recuo e sobre a presença nas lojas de mercadorias produzidas de forma terceirizada:

Você tem lá (na Riachuelo) produtos da nossa fábrica de Natal, da nossa fábrica de Fortaleza, da nossa fábrica do Paraguai, do nosso escritório de Xangai, de um fornecedor terceirizado de uma malharia em Santa Catarina [...]. Com a competitividade 
no pico, na nossa fábrica, em 2010, 90\% dos clientes que entravam na Riachuelo escolhiam uma peça que era fabricada na fábrica de Natal ou de Fortaleza. Eram fábricas imbatíveis. Mas com areia nas engrenagens, exigências, e fechando o cerco burocrático [...] não somos nós que sofremos [...] (ROCHA, 2017, vídeo, 00:24:44$00: 25: 22)$.

Conforme relatórios de divulgação dos resultados do grupo, a produção das fábricas próprias da Guararapes, que alcançava 41 milhões de peças por ano em 2012 - ou 41,70\% do total vendido na Riachuelo - em 2016 ficou em 39,8 milhões de peças, correspondendo a uma fatia de 32,50\%. Em 2017, as duas fábricas no Nordeste representavam menos de $20 \%$ de toda a confecção vendida na rede de lojas (ROCHA, 2017, vídeo, 00:29:19-00:29:23).

\subsection{Gargalos da linha de produção}

A indústria estudada por Marx 150 anos atrás foi marcada pelo uso em larga escala de mão de obra de homens, mulheres e crianças e jornada de trabalho extenuante. O objetivo era manter as engrenagens do capitalismo e gerar o que o autor denomina mais-valia, definida como a formação do valor excedente de uma mercadoria, gerado por meio do trabalho excedente do trabalhador. Marx explica que o trabalhador acrescenta ao material, ao objeto de trabalho, um novo valor por meio do acréscimo de determinada quantidade de trabalho. Ele complementa que, quando o trabalhador opera além dos limites do trabalho necessário à produção de uma mercadoria [...] gera a mais-valia. $\mathrm{O}$ autor classifica essa parte do dia de trabalho de tempo de trabalho excedente e o trabalho nela dispendido de "trabalho excedente" (MARX, 2017, p. 253).

Nesse sistema, homens, mulheres e crianças chegavam a trabalhar mais de quinze horas por dia em determinados segmentos. Casos de doenças e mortes relacionadas à sobrecarga de trabalho e a condições insalubres no ambiente de produção também eram visíveis.

Marx (2017) registra que havia certa resistência dos trabalhadores a esse sistema, que fiscais reportavam os abusos dos detentores do capital, mas pareciam incapazes de detê-los. A descrição de Marx indica dificuldades para conter a voracidade da produção capitalista, uma busca desenfreada por produzir o tempo inteiro e lucrar cada vez mais com isso.

O trabalhador poderia, nesse contexto, ser facilmente substituído e por esse motivo se submetia a tais condições. Duas opções existiam nesse cenário: trabalhar à exaustão ou perder a vaga para outro que estivesse disposto a aceitar a dinâmica capitalista. Trindade (2007) explica que "o desemprego remonta aos primórdios da existência do capitalismo" e "como elucidou Marx, ao suceder-se a produção do sistema de metabolismos de segunda ordem, cria-se uma massa de trabalhadores desocupados, sobrantes, sob a ótica dos detentores dos meios de produção". Esses trabalhadores eram chamados por Marx de "exército industrial de reserva".

A esse respeito, observa Hobsbawm (1977), se um fator dominava a vida dos trabalhadores do século XIX — os trabalhadores da "era do capital" - era a insegurança. É o que demonstra o trecho a seguir: 
Eles não sabiam no princípio da semana quanto iriam levar para casa na sexta-feira. Não sabiam quanto tempo iria durar o emprego atual ou, se viessem a perdê-lo, quando voltariam a encontrar outro e em que condições. [...] Não havia certeza no trabalho nem para os mais especializados (HOBSBAWM, 1977, p. 218)

Mas não era apenas a insegurança que rondava o modo de produção capitalista. Marx escreve em $\mathrm{O}$ Capital:

O capital tem seu próprio impulso vital, o impulso de valorizar-se, de criar mais-valia, de absorver com sua parte constante, com os meios de produção, a maior quantidade possível de trabalho excedente. O capital é trabalho morto que, como um vampiro, se reanima sugando o trabalho vivo, e quanto mais o suga, mais forte se torna (MARX, 2017, p. 271).

Especificamente na Guararapes e nas facções não se veem crianças na linha de produção, mas um grande exército de homens e mulheres distribuídos entre as diversas etapas da confecção de roupas e de outros "artigos de moda". Parte desse "exército" também é registrada perdendo as vagas que ocupavam nas fábricas da grande indústria, concomitantemente ao início da terceirização da etapa de costura das peças.

Outra parte, composta por "ex-trabalhadores", que agora tentam sobreviver como empreendedores que alimentam a grande indústria, vive em completa dependência dessa "gigante", com incertezas em relação à demanda e sem saber se, nesse contexto, conseguirá manter suas atividades no mercado.

Parte desses trabalhadores está fora dos limites das fábricas próprias da Guararapes, mas o Ministério Público do Trabalho afirma que são completamente subordinados a ela. Na ação civil pública, cujo ponto central é o sistema de contratação, o controle exercido sobre essas empresas e o impacto para o trabalhador, o MPT-RN afirma:

\footnotetext{
Ao remeter às facções a estrutura empresarial destinada à costura de roupas, mantendo, no entanto, sobre elas rígido controle administrativo e operacional, a Guararapes simula o mecanismo de externalização de serviços para reduzir o custo de produção, isentar-se do risco da atividade econômica e evadir-se de obrigações fiscais e trabalhistas. Com isso, deixa de admitir diretamente os empregados e de arcar com seus direitos trabalhistas e se omite do dever legal de garantir a adequação do meio ambiente de trabalho em que se desenvolve a atividade central de seu objeto social, em profundo prejuízo ao cumprimento dos direitos fundamentais dos trabalhadores (MPT-RN, 2017, p. 5).
}

O MPT-RN menciona a "ilicitude da intermediação de mão de obra da atividade de costura" por parte da Guararapes e que "as empresas de facção funcionam como verdadeiros departamentos produtivos da empresa contratante, apenas dotados de personalidade jurídica própria e vinculados contratualmente para disfarçar a real subordinação operacional, produtiva e econômica" (MPT-RN, 2017, p. 4).

A ação civil pública detalha que a criação de facções é estimulada pela companhia, diante da expectativa das pequenas empresas de que a demanda lhes será garantida. Essas empresas então: contraem financiamentos no Banco do Nordeste para montar suas estruturas de produção, o que inclui máquinas de 
costura adequadas às necessidades da Guararapes; empregam mão de obra local e assinam contratos em que a grande indústria estabelece de forma unilateral o sistema de trabalho em que irão operar - sem garantir qualquer autonomia às empresas, regularidade de pedidos ou demanda mínima de serviço (MPTRN, 2017, p. 49).

A grande indústria atua como único ou principal cliente dessas fábricas e, conforme detalhado na ação, descredencia, muitas vezes sem aviso prévio, as que não atingem a produtividade exigida ou descumprem obrigações trabalhistas, como o pagamento de salários em dia, por exemplo. Com o encerramento do contrato, as contratadas se veem em meio a dificuldades financeiras que inviabilizam a manutenção de suas atividades e promovem demissões em que os empregados por vezes precisam ir à justiça para receber as verbas a que têm direito.

A capacidade financeira dessas empresas, comprometida em função da dependência praticamente generalizada de um único comprador, já era afetada, segundo o MPT-RN (2017), pela baixa remuneração que obtinham com a prestação dos serviços. $\mathrm{Na}$ época da inspeção, esse pagamento correspondia a $\mathrm{R} \$$ 0,30 por minuto de produção e, para ser garantido, representava, segundo alguns dos costureiros ouvidos nas inspeções do Ministério Público do Trabalho, uma jornada sem pausa para descanso e com necessidade de realização de horas extras para atingir metas de produção (MPT-RN, 2017, p. 74).

A ação descreve:

Com a prefixação do preço do serviço de costura por tempo de produção e com a exigência contratual de altíssima produtividade, a ré impede que as facções concedam, contratualmente, benefícios salariais, o que resulta em redução salarial e estimula a realização de trabalho em jornada extraordinária [...] Cita-se, como exemplo, o caso da facção J.S \& Silva [...] foi visto no sistema que os empregados laboram em horas extras, pois a jornada semanal é de 45 horas [...] a revisora de qualidade [...] respondeu que esporadicamente os trabalhadores fazem horas extras aos sábados, quando há demanda (MPT-RN, 2017, p. 68-69).

Em depoimento reproduzido na ação, outra empregada de facção declara que "nunca gozou férias, e que há horas extras em um sábado por mês". Também foi identificado na facção pagamento parcelado dos salários (MPT-RN, 2017, p. 69).

Ao mesmo tempo, aponta a ação, a grande indústria desencorajava o pagamento de adicionais aos empregados - a exemplo de prêmios de produção para estimular a produtividade - embora oferecesse ela própria esse tipo de "incentivo" em suas fábricas. Essa diferença de tratamento entre os trabalhadores é evidenciada no seguinte trecho:

[...] Nas facções, a Ré apenas permite o pagamento do piso salarial, que é o salário mínimo acrescido de $\mathrm{R} \$ 5,00$ (cinco reais), e proíbe as facções de pagarem prêmio produção, chegando a punir com cancelamento do envio de peças aquelas que pagarem o referido prêmio. Embora entoe o discurso de que se as facções quiserem, podem pagar o prêmio de produção, o fato é que o cálculo do custo da peça a ser costurada não prevê o pagamento de quaisquer outros incentivos financeiros aos empregados, conforme se observa da comunicação da Ré aos faccionistas, informando que o reajuste do preço por minuto de costura observa o percentual de reajuste do salário mínimo [...]. (MPT-RN, 2017, p. 65-66) 
A ação do MPT também apresenta um cenário em que, devido à operação de baixo custo a que são submetidas, as facções deixam de cumprir direitos legais e previstos na convenção coletiva da categoria, conforme detalhado a seguir:

Ao promover a costura de roupas sob regime de intermediação de mão de obra, fraudando a relação de emprego mantida com os respectivos trabalhadores, a Ré reduz o patamar de garantias sociais desses laboristas, violando seus direitos mais elementares. [...] Pressionadas à máxima produtividade e redução de custos trabalhistas, e submetidas à condição de profunda fragilidade econômica, as facções tendem a inadimplir direitos previstos nas normas coletivas da categoria, como cesta básica, plano de saúde, ticket alimentação etc. [...] (MPT-RN, 2017, p. 66).

Segundo a ação civil pública, "é visível que a intermediação de mão de obra", nesse caso, "visa ao barateamento do custo do produto final a ser vendido em suas lojas, com a consequente redução de direitos trabalhistas” (MPT-RN, 2017, p. 67).

O documento observa que os contratos entre as partes são firmados "por adesão" e não garantem regularidade de pedidos nem demanda mínima de serviço para as pequenas produtoras:

De modo que essas empresas funcionam em estado de profunda dependência econômica da contratante, sob seu estrito controle operacional, com reduzidíssima margem de lucro projetada, destituídas de qualquer lastro financeiro para negociar melhores condições de trabalho e para investimento em saúde e segurança do trabalhador (MPT-RN, 2017, p. 3).

O modelo de contratação e operação adotado pela Guararapes, segundo o MPT-RN, "frauda radicalmente o sistema de proteção social do trabalhador, se equiparando para os fins trabalhistas à figura da marchandage, prática de comercialização de mão de obra que reduz o trabalho à condição de mercadoria" e "é abominado no círculo dos países que integram a Organização internacional do Trabalho - OIT" (MPT-RN., 2017, p. 59).

A ação ainda fornece elementos que mostram o efeito do grau de dependência mantido por facções e trabalhadores em relação à Guararapes:

[...] extrai-se que, quando a Ré deixa de enviar peças para as facções, há encerramento, de fato, de suas atividades, dada a dependência econômica exclusiva da Ré. [...] Dos depoimentos dos faccionistas que prestam serviços com exclusividade para a empresa Ré, extrai-se sempre a mesma realidade: quando a Ré deixa de encaminhar peças para costura, há o encerramento das atividades das facções e os empregados são despedidos, sem o recebimento das verbas rescisórias [...] (MP'T-RN, 2017, p. 16).

\subsection{A ação pública como expressão institucional da luta de classes}

A ação civil pública do Ministério Público levou Flávio Rocha, da Guararapes, a criticar a atuação do órgão em entrevistas concedidas a veículos de comunicação e em seus perfis nas redes sociais. Um dos argumentos do empresário é que não existe luta de classes. A ação do MPT é, na declaração de Rocha, explicada por um movimento antirreformista, em referência à reforma do trabalho e à lei da terceirização aprovadas em 2017 no Brasil: 
Existe um movimento antirreformista extremamente combativo e nós sentimos na própria pele a força desse movimento, que visa impedir uma das maiores conquistas recentes da sociedade que são a reforma trabalhista e a lei da terceirização. Nós tivemos uma autuação de $R \$ 38$ milhões, na nossa unidade de Natal, sem que tenhamos infringido nenhum artigo da lei. Não há nenhum artigo, nenhuma hora extra que deixou de ser paga, [...] é uma situação completamente sui generes. É o agente da lei que está contra a lei. É o Ministério Público do Trabalho que está se manifestando abertamente contra a reforma trabalhista e contra a terceirização (ROCHA, 2017, vídeo 00:15:14-00:16:07).

O empresário destaca que o pedido do órgão para que a Guararapes assuma a contratação direta e a responsabilidade pelos trabalhadores das facções seria inviável. Os argumentos ressaltam aquilo que, segundo ele, teria motivado a autuação do grupo:

[Isso ocorreu] Por uma tese doutrinária, que é a negação da terceirização, que é a subordinação estrutural. É uma tese acadêmica exótica que mostra realmente a forma de agir. Essa tese aplicada no ABC Paulista, em São Bernardo, extinguiria imediatamente a indústria automobilística, porque ela consideraria que os fornecedores de vidros, de amortecedores, de pneus da General Motors, devem ser incorporados pela empresa mãe. Você imagina a Fiat, em Betim, com seus 50 fornecedores que a cercam, tendo que do dia pra noite incorporar na sua folha de pagamento todas aquelas carteiras de trabalho? Isso iria virar um gigante inadministrável de 200 mil a 250 mil trabalhadores. Isso é a negação do capitalismo. A negação do livre mercado. É por isso que estamos sendo autuados (ROCHA, 2017, grifo nosso, vídeo, 00:16:26$00: 17: 43)$.

Além de afirmar que essa ação é resultado de um movimento antirreformista e antiterceirização, Rocha enfatiza que os empregados das facções estão "solidários" aos patrões e que não existe luta de classes - um dos elementos discutidos na teoria marxista.

Esse tema foi debatido em entrevista concedida ao programa Roda Viva, em setembro de 2017, quando o referido empresário foi questionado sobre o que teria levado milhares de trabalhadores das facções a irem às ruas em manifestações em defesa do Pró-Sertão. Segundo ele, as manifestações representam uma "pequena revolução", conforme detalhado a seguir:

Está em curso, eu diria, que uma pequena revolução no Rio Grande do Norte, que deve estar levando à reflexão boa parte dos analistas, dos cientistas políticos, dos sociólogos, que tinham aquela versão do nós contra eles, essa versão tacanha da luta de classes. Isso ficou claramente desmoralizado no Rio Grande do Norte. Eu acho que até o Ministério Público do Trabalho tem essa visão, se vê na condição de protetor do trabalhador oprimido contra o patrão ganancioso e eu acho que eles devem ter se surpreendido. Porque foram desautorizados. Essas mobilizações estão acontecendo constantemente [...] a mensagem [de donos de facções, trabalhadores e fornecedores] é: nos deixem trabalhar [...] (ROCHA, 2017, vídeo, 00:21:46-00:22:53)

Rocha (2007, vídeo, 00:25:54-00:26:51) reforça que o movimento “foi absolutamente espontâneo. [...] E que entrou em erupção um sentimento de solidariedade aos patrões que as pessoas dessa burocracia acham que não existe. Acham que não existe trabalhador que gosta de patrão". Com base em Marx, Yildirim (1979) observa, no entanto, que a luta de classes existe e ganha força na era capitalista.

De acordo com Marx, trabalhadores e capitalistas têm lutado dentro da era capitalista. Como resultado desse processo, a classe trabalhadora torna-se uma classe independente 
poderosa e organizada que possui sindicatos e partidos políticos fortes nos países capitalistas com industrialização avançada (YILDIRIM, 1979, p. 9, tradução nossa).

Exemplos recentes dessa luta de classes no Brasil foram vistos à época das discussões e da votação da lei da terceirização e da reforma trabalhista. No caso da reforma trabalhista, aprovada em julho de 2017, com vigência a partir de novembro do mesmo ano, centrais sindicais, trabalhadores e outros representantes da sociedade civil realizaram atos em diversos estados apontando riscos de perda de direitos trabalhistas, de precarização na relação entre capital e trabalho, e de enfraquecimento dos sindicatos.

O conflito entre as classes também tem-se manifestado na justiça. Segundo o Ministério Público do Trabalho, "a conduta da Guararapes conduziu os empregados para a judicialização de seus pleitos rescisórios” (MPT-RN, 2017, p. 90). O órgão calcula a existência de, pelo menos, 249 ações trabalhistas contra as facções e a Ré, por inadimplência de verbas trabalhistas".

Consequências desse cenário são especificadas nos trechos a seguir, extraídos da ação civil pública:

[...] A brusca suspensão do envio de peças, promovida pela Ré, com relação a algumas facções, enseja o encerramento de suas atividades, com consequente despedimento dos empregados, por força da extrema dependência econômica dos microempresários. Esse fato é facilmente comprovado por meio das notas fiscais encaminhadas pela Receita Federal [...] e pelo número de ações trabalhistas ajuizadas na Vara do Trabalho de Caicó [...] (MPT-RN, 2017, p. 70).

Na entrevista concedida ao Roda Viva, Flávio Rocha tenta derrubar a teoria da luta de classes com o argumento de que os empregados de facções que foram às ruas defender o programa de terceirização da costura agiram de forma espontânea. No entanto, deixa de mencionar que esses trabalhadores protagonizam essa história na condição do "oprimido", que tem sua força de trabalho explorada e seus direitos expropriados, mas precisa preservar o emprego, tendo em vista a permanência das altas taxas de desemprego no Brasil. Além disso, as cidades do interior nordestino, em especial do Rio Grande do Norte, não apresentam alternativas viáveis de trabalho digno.

Marx começou a discutir o conceito de classe no terceiro volume de O Capital, mas não chegou a concluir esse debate, o que levanta a necessidade de o tema ser estudado também em suas outras obras, segundo Yildirim (1979). No capítulo (incompleto) de O Capital, Marx afirma:

Os proprietários apenas da força de trabalho, os proprietários do capital, e os donos de terras, cujas fontes de renda são, respectivamente, salários, lucro e aluguel de terras, em outras palavras, trabalhadores assalariados, capitalistas e proprietários de terras, constituem as três grandes classes da sociedade moderna baseada no modo capitalista de produção (MARX, apud YILDIRIM, 1979, p. 15)

Ainda segundo Yildirim (1979, p. 08), “a lacuna econômica entre a burguesia [os capitalistas] e o proletariado, de acordo com Marx, vai se tornar cada vez maior e a razão para isso é que a mais-valia que a classe trabalhadora cria é expropriada pela classe capitalista" [tradução nossa]. O autor vai além:

A expropriação da mais-valia é o resultado da acumulação do capital na sociedade capitalista. Enquanto a acumulação continuar, a riqueza da classe capitalista vai 
aumentar. Como resultado desse processo, a distância econômica, nas diferentes esferas [...] aumenta na sociedade capitalista (YILDIRIM, 1979, p. 8).

Em o Manifesto Comunista, Marx e Engels lembram que "a história de todas as sociedades [...] tem sido a história das lutas de classes”. A esse respeito, escrevem:

Homem livre e escravo, patrício e plebeu, barão e servo, mestre de corporação e companheiro, numa palavra, opressores e oprimidos, em constante oposição, têm vivido numa guerra ininterrupta, ora franca, ora disfarçada [...] a sociedade burguesa moderna, que brotou das ruínas da sociedade feudal, não suplantou os velhos antagonismos de classe. Ela colocou no lugar novas classes, nova condições de opressão, novas formas de luta (MARX, ENGELS, S/D, p. 7-8].

No Rio Grande do Norte, na linha de produção de sua maior indústria, essa luta de classes também se mostra uma realidade que afeta milhares de trabalhadores. Não se deve olvidar que, no conflito Guararapes (capital) versus trabalhadores e a interveniência do MPT-RN, a solução para os trabalhadores é “determinada pela expressão do conjunto de processos de repressão, de integração, de dominação e de regulação que procedem do aparelho de Estado” (PEREIRA, 2008, p. 38).

O conflito não será solucionado com a ACP impetrada pelo MPT-RN. No máximo, os trabalhadores explorados receberam pequenas restituições financeiras dos valores que lhes foram arrancados na expropriação capitalista. O Estado, representado pelo Ministério Público do Trabalho, atua contra o capital com a finalidade de intervir no conflito de classes. Essa intervenção não ocorre com o intuito de arbitrar as diferenças entre as classes, mas para evitar que estas se destruam no conflito.

\section{Breve conclusão}

Um século e meio depois, aquilo que Karl Marx descreveu como a busca desmedida do capital para ampliar seus ganhos significou, na prática, a exploração da força de trabalho e a expropriação de direitos, não só trabalhistas, mas também sociais.

Transcorrido todo esse tempo, discurso e práticas comuns entre capitalistas, mas amplamente criticados por Marx, não se "descolaram” da operação da indústria. O caso que envolve a Guararapes e a contratação de facções, no Rio Grande do Norte, ajuda a exemplificar isso.

Nesse regime, em que se transfere a responsabilidade pela costura de peças de vestuário para as pequenas indústrias subcontratadas, apontam-se possíveis irregularidades, cujo propósito é acelerar a produção da grande indústria com redução de custos e consequente expansão do capital - a chamada mais-valia.

De um lado, apresenta-se a grande indústria, detentora dos meios de produção e de um lucro milionário, a contratante dos serviços. De outro, pequenos empresários e trabalhadores distribuídos em áreas deprimidas economicamente, em que faltam alternativas de emprego e, na maioria dos casos, em situação de completa dependência da grande indústria. 
O desemprego, a precarização dos postos de trabalho nas facções e toda sorte de pressão e opressão vivenciada pelos trabalhadores dessas instituições expressam a questão social gerada pela exploração e expropriação do capitalismo, em sua forma particular, materializada nas relações sociais entre trabalhadores, facções, Guararapes.

Para minimizar as pressões e opressões desse contexto particular existem as instituições do estado, como o MPT-RN e a Justiça do Trabalho, por exemplo, mas é muito difícil extenuar os impactos da opressão, conforme se discutiu neste artigo, pois os capitalistas, nesse caso, a Guararapes, refutam a possibilidade de banir o fantasma da expropriação via pagamento efetivo dos direitos dos trabalhadores. Além disso, procuram manter sua força coercitiva sobre as instituições estatais, as quais poderiam pender para os trabalhadores.

Estabelece-se, portanto, o eterno conflito de classes, no qual o Estado, por meio de suas instituições, apresenta-se como a arena de disputa. A luta pelo controle do discurso sobre a "verdade processual" garante ao vencedor alguns milhões de reais, significativos para os trabalhadores, mas não financeiramente representativo para o capital. Trata-se, no entanto, de uma dimensão política elevada. A vitória do MPT-RN e dos trabalhadores abriria espaço para novas reinvindicações. É uma questão de "princípios” para o capital não perder a disputa jurídica. Para isso, cabe apelar para o marketing, para a propaganda ou partir para conflitos que personalizem e ideologizem a questão.

O intuito deste trabalho não foi fazer as ilações possíveis e pensáveis sobre a solução jurídica da ação pública, mas tão somente advogar que a situação vai além de uma simples disputa por verbas indenizatórias trabalhistas. Prova disso é que os representantes do capital apelam para toda sorte de instrumentos para postergar, desclassificar, injuriar e difamar os envolvidos na ação.

\section{Referências}

AMORIM, Jairo. Entrevista à Tribuna do Norte, para a reportagem “Costurando o Desenvolvimento "Pequenas" entram em campo para impulsionar grande indústria". 2013. Disponível em: $<<$ http://www.tribunadonorte.com.br/costurandoodesenvolvimento/ $>$ e entre 4 minutos e 53 segundos e 5 minutos e 22 , em: < https://www.youtube.com/watch?time continue=2\&v=PJrDgzrd9iI $>>$ Acesso em: 15 nov. 2017.

ALVES, Maciel. Depoimento para o vídeo “A linha que move vidas”, da Tribuna do Norte. Disponível em: << https://www.youtube.com/watch?v=fwbA5TV3x38>>Acesso em: 02 dez. 2017

A REPÚBLICA. Pró-sertão deve gerar 8.400 empregos no setor têxtil até 2018. 12 jun 2015. Ano 1, número: 70. Disponível em < http://www.arepublica.rn.gov.br/pdf/a\%20republica $\% 2070 . p d f>>$,

CECI, Mariana. A indústria têxtil resiste no semiárido. Tribuna do Norte. Natal, 02 ago 2018.

Disponível em < http://www.tribunadonorte.com.br/noticia/a-indaostria-ta-xtil-resiste-no-semiarido $/ 404082>>$

CILENE, Joilma. Depoimento para o vídeo “A linha que move vidas”, da Tribuna do Norte.

Disponível em: << https://www.youtube.com/watch?v=fwbA5TV3x38>> Acesso em: 02 dez. 2017 
FEDERAÇÃO DAS INDÚSTRIAS DO RIO GRANDE DO NORTE. Municípios do semiárido temem fechamento de facções de costura. Disponível em: $<<\underline{\text { http: / } / \text { www.fiern.org.br/municipios- }}$ semiarido-temem-fechamento-de-faccoes-de-costura/>>. Acesso em: 14 nov. 2017.

, Facções de Confecções: Municípios do Seridó têm os melhores IDHs do Rio Grande do Norte. Disponível em: $<$ https://www.fiern.org.br/faccoes-de-confeccoes-municipios-serido-tem-osmelhores-idhs-rio-grande-norte/>> Acesso em 04 out. 2020.

GALINDO, Leonardo da Silva. Uso corporativo do território e "facções" de costura: a reorganização espacial do setor de confecções de artigos do vestuário no Rio Grande do Norte. 2018. 243f. Dissertação (Mestrado em Geografia) - Centro de Ciências Humanas, Letras e Artes, Universidade Federal do Rio Grande do Norte, Natal, 2018. Disponível em $<<$ https://repositorio.ufrn.br/handle/123456789/25502 >>

GOVERNO DO RN. Governo lança programa Pró-Sertão nesta segunda e prevê a criação de 20.000 empregos diretos até 2018. Natal, 06 ago 2013. Facebook. Disponível em $<<$ https://www.facebook.com/GovernodoRN/photos/a.443900935697279/500892293331476/>>

GOVERNO DO RN. Cadastro no programa "Pró-Sertão já está sendo realizado na Secretaria do Desenvolvimento Econômico (Sedec). Inscreva-se!. Natal, 16 ago 2013. Facebook. Disponível em $<<$ https://www.facebook.com/GovernodoRN/photos/a.443900935697279/505614566192582>>

HOBSBAWM, E. A Era do Capital. Disponível em: $<<\underline{\text { http://lelivros.love/book/baixar-livro-a-era-do- }}$ capital-1848-1875-eric-j-hobsbawm-em-pdf-epub-e-mobi-ou-ler-online/>> Acesso em 06 de dezembro de 2018.

GUARARAPES. Apresentação dos Resultados do 4T dos anos 2011, 2012, 2013, 2014, 2015 e 2016. Disponível em:

$<<$ http://ri.riachuelo.com.br/ListGroup.aspx?idCanal=/wnF2BAlYDwVLU19IB0mog==\&ano=2014> $>$. Acesso em 01 e 02 dez. 2017.

Resultados 2013. Disponível em:

$<<$ https://ri.riachuelo.com.br/listresultados.aspx?idCanal=SEIpANecjCAH5uaTCxPYdw $>>$ Acesso em 23 de julho de 2018

INSTITUTO BRASILEIRO DE GEOGRAFIA E ESTAtístiCA (IBGE) - Pesquisa Mensal de Comércio, dezembro 2013. Disponível em:

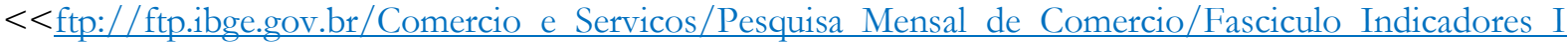
BGE/2013/>>. Acesso em: 01 dez. 2017

Cadastro Central de Empresas (CEMPRE), base de dados online disponível em $<<$ https://sidra.ibge.gov.br/tabela/992>> Acesso em 08 de junho de 2019

INVERNIZZI, Noela. Qualificação e Novas Formas de Controle da Força de Trabalho no Processo de Reestruturação da Indústria Brasileira: Tendências dos Últimos Vinte Anos. Disponível em: $<<$ http://www.anped.org.br/sites/default/files/gt 09 09.pdf $>>$. Acesso em: 03 dez. 2017

KELLER, Roberto Ranna; GARCIA, Nilson Marcos Dias. A “Terceirização” da Produção na Indústria Curitibana do Vestuário: Alívio e Desespero. Revista Pegada - vol. 16, n. especial. Disponível em: $<<$ https://revista.fct.unesp.br/index.php/pegada/article/view/3527>> Acesso em 19 set. 2020.

KROST, Oscar; BRANDÃO, Leonardo. A Precarização das Condições de Trabalho em "Facções" do Ramo Têxtil/Vestuário em Blumenau/SC: A Face Oculta da Reestruturação Produtiva. 
Revista DRd - Desenvolvimento Regional em debate, v. 7, n. 1, p. 164-180, maio 2017. Disponível em $<<\underline{\text { https://dialnet.unirioja.es/servlet/articulo? codigo=5976440 }}>>$ Acesso em 20 set. 2020.

MARX, Karl. O Capital. Vol. I. Rio de Janeiro: Civilização Brasileira, 2017

MARX, Karl; ENGELS, Friedrich. Manifesto comunista. Disponível em:

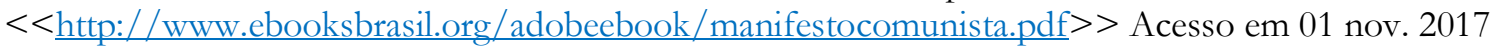

MANDEL, Ernest. An Introduction to Marxist Economic Theory. Disponível em: $<<$ http://www.readingfromtheleft.com/PDF/Mandel-EconTheory.pdf $>>$ Acesso em: 05 dez. 2017. p. 28

MARCELINO, Paula; CAVALCANTE, Sávio. Por uma definição de terceirização. Cad. CRH [online]. 2012, vol.25, n.65, pp.331-346. Disponível em $<<$ https://www.scielo.br/scielo.php?script=sci_arttext\&pid=S0103-49792012000200010>>

MOURA, Renata; MENDES, Andrielle. "Pequenas" entram em campo para impulsionar grande indústria. Tribuna do Norte. 15 set 2013. Disponível em $<<$ http://www.tribunadonorte.com.br/costurandoodesenvolvimento/\#mercado $>>$

MOURA, Renata; VASCONCELOS, Sara. 'Tempo fechado' para o emprego. Tribuna do Norte. 06 mar 2016. Disponível em < http://www.tribunadonorte.com.br/noticia/a-tempo-fechadoa-para-oemprego/339707>>

MPT-RN. Ação Civil Pública 0000694-45.2017.5.21.0007, movida pelo MINISTÉRIO PÚBLICO DO TRABALHO (MPT-RN)). Ação Civil Pública. Recebida por e-mail da assessora de imprensa do órgão, a jornalista Tatiana de Souza Lima, em 06 dez. 2017.

PALMEIRA SOBRINHO, Zéu. Reestruturação Produtiva e Terceirização: o caso dos trabalhadores das empresas contratadas pela Petrobras no RN. 259 f. Tese (Doutorado em Ciências Sociais) - Universidade Federal do Rio Grande do Norte, Natal, RN, 2006. Disponível em $<<$ https://repositorio.ufrn.br/jspui/handle/123456789/13838>> Acesso em 01 de outubro de 2020.

PEREIRA, William E. N.Reestruturação do Setor Industrial e Transformação do Espaço Urbano de Campina Grande - PB a partir dos anos 1990. Tese de doutoramento em Ciências Sociais. CCHLA. UFRN, 2008.

PRODANOV, Cleber Cristiano; DE FREITAS, Ernani Cesar. Metodologia do trabalho científico: métodos e técnicas da pesquisa e do trabalho acadêmico-2 ${ }^{a}$ Edição. Editora Feevale, 2013. Disponível em $<<$ https://drive.google.com/file/d/11p5R-Ry'Trt6X8UPoq2jJ8gO3UEfM JJd/view $>>$

ROCHA, Flávio. Entrevista ao programa Roda Viva. Disponível em: $<<$ https://www.youtube.com/watch?v=UedUjFG8WwA $>>$ Acesso em: 15 nov. 2017.

SEBRAE. Pró-Sertão: Incentivo à economia do Semiárido do Rio Grande do Norte. Dez 2017. Disponível em $<<$ https://www.rn.sebrae.com.br/loja/inc/pdfs/PEQUENAS-EMPRESAS.pdf $>>$

, Estudo de competitividade dos setores têxtil e confeccionista no Estado do Rio Grande do Norte. Dez 2016. Natal: SEBRAE/RN, 2017. Disponível em: << https://m.sebrae.com.br/Sebrae/Portal\%20Sebrae/UFs/RN/Anexos/SEBRAE\%20$\% 20$ Estudo $\% 20$ Competitividade $\% 20$ Setor $\% 20$ Textil $\% 20$ do $\% 20$ Rio $\% 20$ Grande $\% 20$ do $\% 20$ Norte $\% 20201$ 6\%20-\%20FINAL.pdf $>>$

SEDEC (SECRETARIA DE DESENVOLVIMENTO ECONÔMICO DO RIO GRANDE DO NORTE). Pró-Sertão - Programa de Interiorização da Indústria Têxtil. Disponível em: 
$<<\underline{\text { http://sedec.rn.gov.br/Conteudo.asp? TRAN }=I T E M \& T A R G=15791 \& A C T=\text { null\&PAGE }=0 \& P A R}$ $\mathrm{M}=$ null\&LBL $=\operatorname{Pr} \% \mathrm{C} 3 \% \mathrm{~B} 3-\mathrm{Sert} \% \mathrm{C} 3 \% \mathrm{~A} 3 \mathrm{O}>>$. Acesso em: 14 nov. 2017.

SMITH, Adam. A riqueza das nações. Disponível em:

$<<$ https://direitasja.files.wordpress.com/2012/02/adam-smith-a-riqueza-das-nac3a7c3b5es-vol-i.pdf.>> Acesso em: 06 dez. 2017.

TRINDADE, Hiago. Crise do capital, exército industrial de reserva

e precariado no Brasil contemporâneo. Serv. Soc. Soc. [online], 2017, n. 129, pp. 225-244. Disponível em: $<<$ http://www.scielo.br/pdf/sssoc/n129/0101-6628-sssoc-129-0225.pdf $>>$. Acesso em: 03 dez. 2017

YILDIRIM, Osman Nuri. Marx's polarization theory and class struggle in advanced industrial capitalist society. 1979. Dissertação de doutorado. Acessado na The British Library, em Londres, em 03 dez. 2017.

Recebido em: 13 de novembro de 2019. Aprovado em: 30 de julho de 2020. 